\title{
Aneurysmectomy for Crawford's Type-I Thoracoabdominal Aortic Aneurysm Using Gelatin Impregnated Woven Vascular Prosthesis under Mild Hypothermic Extracorporeal Circulation: A Video Presentation
}

\author{
Ujjwal K. Chowdhury ${ }^{1, \odot}$ Sukhjeet Singh ${ }^{1}$ Niwin George ${ }^{1}$ Poonam Malhotra Kapoor ${ }^{2}$ \\ Srikant Sharma ${ }^{1}$ Niraj Nirmal Pandey ${ }^{3}$ Sanjoy Sengupta ${ }^{1}$ Prateek Vaswani ${ }^{1}$
}

${ }^{1}$ Departments of Cardiothoracic and Vascular Surgery, All India Institute of Medical Sciences, New Delhi, India

${ }^{2}$ Departments of Cardiac Anaesthesia, All India Institute of Medical Sciences, New Delhi, India

${ }^{3}$ Departments of Cardiac Radiology, All India Institute of Medical Sciences, New Delhi, India

J Card Crit Care:2020;4:136-139
Address for correspondence Dr. Ujjwal Kumar Chowdhury, MCh, Diplomate NB, Department of Cardiothoracic and Vascular Surgery, All India Institute of Medical Sciences, New Delhi-110029, India (e-mail: ujjwalchow@rediffmail.com, ujjwalchowdhury@gmail.com).
Abstract
Keywords
- aneurysmectomy
- Crawford's type-I thoracoabdominal aortic aneurysm
- gelatin impregnated woven vascular prosthesis
- mild hypothermic extracorporeal circulation

Based on the risk of ischemic injury to the spinal cord and the risk of renal failure and mortality, Crawford and colleagues classified thoracoabdominal aortic aneurysms into four extents. Type I thoracoabdominal aortic aneurysms involved the descending thoracic aorta proximal to the level of 6 th rib to above the renal arteries; type II extends from the proximal descending thoracic aorta above the level of T6 to below the renal arteries; type III extends from below the level of T6 in the descending aorta and a variable extent in the abdominal aorta; type IV thoracoabdominal aortic aneurysm involved the abdominal aorta without involvement of the descending aorta.

\section{Introduction}

Based on the risk of ischemic injury to the spinal cord and the risk of renal failure and mortality, Crawford and colleagues classified thoracoabdominal aortic aneurysms into four extents. ${ }^{1-4}$ Type I thoracoabdominal aortic aneurysms involved the descending thoracic aorta proximal to the level of 6th rib to above the renal arteries; type II extends from the proximal descending thoracic aorta above the level of T6

published online November 4, 2020
DOI https://doi.org/ 10.1055/s-0040-1721184 ISSN 2457-0206. to below the renal arteries; type III extends from below the level of T6 in the descending aorta and a variable extent in the abdominal aorta; type IV thoracoabdominal aortic aneurysm involved the abdominal aorta without involvement of the descending aorta. ${ }^{1-4}$

Medial degenerative aneurysms of the descending thoracic aorta or thoracoabdominal aorta are associated with loss of elastic tissues, and deposition of atheromatous material and clot formation within the aneurysms. The intra-aneurysmal

(C) 2020. Official Publication of The Simulation Society (TSS), accredited by International Society of Cardiovascular Ultrasound (ISCU).

This is an open access article published by Thieme under the terms of the Creative Commons Attribution-NonDerivative-NonCommercial-License, permitting copying and reproduction so long as the original work is given appropriate credit. Contents may not be used for commercial purposes, or adapted, remixed, transformed or built upon. (https://creativecommons.org/ licenses/by-nc-nd/4.0/)

Thieme Medical and Scientific Publishers Pvt. Ltd., A-12, 2nd Floor, Sector 2, Noida-201301 UP, India . 
clot causes obstruction of the intercostal and lumbar vessels, thereby compromising with the viability of the spinal cord. The collateral blood supply to the spinal cord become critical for its viability. With progression of the atherosclerotic disease process, the visceral arteries, namely, renal artery, celiac artery and superior mesenteric artery gets stenosed/occluded. ${ }^{5-7}$

The late presenters may present with pancreatitis, abdominal angina, bowel infarction, intermittent claudication, "trash foot," and progressive renal failure. In patients with extensive atherosclerosis/calcification, the aorta and the visceral artery origins need to be endarterectomised. ${ }^{1-4}$ In cases of long segment stenosis, concomitant visceral bypass grafts may have to be performed. The field of endovascular stent grafting is rapidly expanding and developing and is useful in select instances of high-risk thoracoabdominal aortic aneurysms. ${ }^{1-4}$ Although spinal cord is protected from ischemic damage in coarctation of aorta, the collateral circulation remains insufficient for prolonged temporary occlusion, which is required for resection of aortic aneurysm. ${ }^{5-7}$

Published literature documents several ingenious techniques to prevent ischemic injury to the spinal cord. The techniques include the following:

- Gott's aorto-aortic heparin-coated vascular shunt. ${ }^{8}$

- Atriofemoral bypass with an interposed mechanical pump or an oxygenator in the circuit. ${ }^{9}$

- Controlled extracorporeal circulation as was practiced by Denton A Cooley in 1957. ${ }^{10}$

- Femoro-femoral bypass with an interposed oxygenator. ${ }^{11}$

- A Gott's tube between left ventricular apex and lower half of body. ${ }^{12}$

Although the above techniques were beneficial in preventing paraplegia and reducing strain on the left ventricle in the hands of several investigators across the world, they have all introduced additional complications and have slowly fallen into disfavor. ${ }^{13-15}$

Other than femoro-femoral bypass and atriofemoral bypass, majority of the techniques enunciated above have all introduced additional complications and have slowly fallen into disfavor. ${ }^{13-15}$ The Texas Heart Institute Group practiced simple aortic cross-clamping with expeditious removal of the aneurysm without any support measures and published their clinical observations that indicate that periods of 30 minutes of aortic occlusion was well-tolerated with a low incidence of paraplegia. ${ }^{13-15}$ We do not have any experience in using this technique.

There have been considerable improvements of surgical results of thoracoabdominal aneurysms over the period of years. In a series of 1509 patients with the thoracoabdominal aneurysms operated since 1986, Svensson and colleagues from the Cleveland Clinic published a mortality of $8 \%$ and the risk of paraplegia/paraparesis was $16 \%{ }^{16}$ The Crawford type II thoracoabdominal aortic aneurysm continue to have a high risk of mortality with an increased risk of paraplegia/ paraparesis. ${ }^{16,17}$ The risk of developing paralysis in Crawford's type I aneurysm varied according to whether the aortic involvement was below the celiac artery. ${ }^{16,17}$ In the long-term follow-up in patients undergoing all types of aortic surgery, whether ascending aortic arch, descending thoracic aorta, thoracoabdominal aorta, or abdominal aorta for aortic dissection, the 5 -year survival has been $60 \%{ }^{1-4}$

\section{Case}

We present herein a 54-year old hyperactive male patient presented with persistent nonradiating, noncolicky pain in the upper abdominal and back of 4 years duration. There was no history of trauma or chest infection. CT angiography revealed normal coronaries, normal-sized ascending aorta, aortic arch and proximal descending thoracic aorta. There was a large multiloculated $(10 \times 5 \mathrm{~cm})$ fusiform aneurysm involving the abdominal aorta from the level of 6th rib to above the renal arteries (Crawford type I). The celiac and superior mesenteric arteries were arising from the aneurysmal sac and were occluded. The collateral supply was from the inferior mesenteric artery. The renal arteries, abdominal aortic bifurcation, and the common iliac arteries were normal. The results of the pulmonary function tests were within normal limits.

\section{Surgical Techniques}

\section{The Operation: Position and Surgical Approach}

The operation was performed with the patient in a $45^{\circ}$ lateral position, so that access can be made to the proximal thoracic aorta through the thoracotomy incision and also to the common femoral vessels for femoral arteriovenous cannulation. ( - Video 1)

The initial thoracic incision was made through the sixth intercostal space, continuing downward to the midline in the abdomen, and then extending through the linea alba to a point below the umbilicus. The cartilaginous costal margin was divided with bone shears. A self-retaining retractor was placed in the thoracotomy incision, and the diaphragm was opened 4 to $6 \mathrm{~cm}$ to facilitate exposure of the proximal abdominal aorta. The diaphragm was not incised deeply to the level of aortic hiatus to avoid the possibility of phrenic nerve injury.

The lesion was inspected to determine the proximal and distal extent. The proximal thoracic aorta was then mobilized and looped using an umbilical tape. The lateral gutter of the peritoneum was opened at a point lateral and posterior to the descending colon and spleen, and total evisceration of the abdominal viscera including the jejunum, ileum, left kidney and spleen was done. Both common iliac arteries were dissected and looped using an umbilical tape, avoiding injury to the common iliac veins.

A double-lumen endotracheal tube allowed collapse of the left lung, thereby facilitating the operation. The right lung, which is larger than the left, provided adequate ventilation during intrathoracic dissection. 


\section{Isolation of the Vagus and Left Phrenic Nerve}

The vagus nerve pedicle was dissected away from the descending thoracic aorta and looped. The left phrenic nerve pedicle was dissected and isolated using an umbilical tape.

\section{Exposure and Cannulation of the Femoral Artery and Femoral Vein}

An infrainguinal vertical incision was made over the right femoral artery. Both right femoral artery and right femoral vein were dissected and looped to facilitate later cannulation. Following systemic heparinization, elective femoral arteriovenous cannulation was performed using long femoral arterial and venous cannulae (Edwards Lifesciences, LLC, One Edwards Way, Irvine, CA, USA).

\section{Cannulation of the Proximal Descending Thoracic Aorta}

The descending thoracic aorta above the aneurysm was cannulated and connected to the bypass circuit for antegrade aortic perfusion. The femoral arterial perfusion was used for distal aortic perfusion.

\section{Completion of the Aortic Dissection under Controlled Extracorporeal Circulation}

Under normothermic controlled extracorporeal circulation, the descending thoracic aorta above and below the aneurysm was dissected for proximal and distal aortic control. Meticulous attention was exercised to not injure the intercostal arteries during the process of dissection.

\section{Cross-clamping of the Descending Thoracic Aorta above the Aneurysm}

The descending thoracic aorta was cross-clamped proximally $2 \mathrm{~cm}$ above the aneurysm. The systolic pressure of the upper half of the body was maintained around $140 \mathrm{mmHg}$.

\section{Proximal Graft Aortic Anastomosis}

The descending thoracic aorta was incised above the aneurysm and $14 \mathrm{~cm}$ segment of gelatin impregnated woven vascular prosthesis (Gelweave, Vascutek Ltd., a Terumo Company, Scotland, UK) size $26 \mathrm{~mm}$ was used for restoration of aortic continuity. The graft was sutured using 4-0 polypropylene sutures (Johnson and Johnson Ltd., Ethicon, LLC, San Lorenzo, USA) and reinforced with Teflon pledgets as and when required. The graft was sutured using the interposition technique.

\section{Aneurysmectomy and Removal of Intra-aneurysmal Clot}

The abdominal aorta was cross-clamped above the origin of the renal arteries. The thoracoabdominal aneurysm was incised longitudinally away from the origin of the visceral arteries. All intra-aneurysmal clots were evacuated and irrigated using cold saline. The celiac and superior mesenteric arteries were chronically occluded and not perfused.

\section{Distal Graft Aortic Anastomosis}

Distal anastomosis was performed by inclusion technique using 4-0 polypropylene suture with support of Teflon pledgets as considered necessary. Reimplantation of the celiac and superior mesenteric arteries were not required, since the collateral circulation through the inferior mesenteric artery was adequate. After securing hemostasis and ensuring distal aortic perfusion, the patient was separated from cardiopulmonary bypass and successfully decannulated. ( - Video 1)

\section{Video 1}

Thoracoabdominal aneurysm_9_min__rev. Online content including video sequences viewable at:https:// www.thieme-connect.com/products/ejournals/html/10.1 055/s-0040-1721184.

\section{Short- and Long-term Result}

The postoperative recovery was uneventful. Follow-up visit at the 36th month revealed the patient as belonging to New York Heart Association functional class I with good biventricular function, normal renal function, and no neurological deficit.

\section{Conclusions}

The potential benefits of this dual arterial cannulation are excellent operative exposure, maintenance of perfusion to all vital organs including brain, avoidance of circulatory arrest, and performance of the operative procedure under controlled conditions. Aneurysmectomy and suturing of the patch can be performed under optimal visualization, achieving perfect hemostasis.

\section{Funding}

The authors received no financial support for the research, authorship, and/or publication of this article.

\section{Conflicts of Interest}

The author(s) declared no potential conflicts of interest with respect to the research, authorship, and/or publication of the article.

\section{References}

1 Crawford ES, Snyder DM, Cho GC. Roehm JOF Jr. Progress in treatment of thoracoabdominal and abdominal aortic aneurysms involving celiac, superior mesenteric, and renal arteries. Ann Surg 1978;188(3):404-422

2 Svensson LG, Crawford ES, Hess KR, Coselli JS, Safi HJ. Thoracoabdominal aortic aneurysms associated with celiac, 
superior mesenteric, and renal artery occlusive disease: methods and analysis of results in 271 patients. J Vasc Surg 1992; 16(3):378-389, discussion 389-390

3 Svensson LG, Coselli JS, Safi HJ, Hess KR, Crawford ES. Appraisal of adjuncts to prevent acute renal failure after surgery on the thoracic or thoracoabdominal aorta. J Vasc Surg 1989; 10(3):230-239

4 Svensson LG, Hess KR, Coselli JS, Safi HJ. Influence of segmental arteries, extent, and atriofemoral bypass on postoperative paraplegia after thoracoabdominal aortic operations. J Vasc Surg 1994;20(2):255-262

5 Selle JG, Robicsek F, Daugherty HK, Cook JW. Thoracoabdominal aortic aneurysms. A review and current status. Ann Surg 1979; 189(2):158-164

6 Gross RE, Hufnagel CA. Surgical correction for coarctation of the aorta. Surgery $1945 ; 18: 673-678$

7 Crafoord C, Nylin G. Congenital coarctation of the aorta and its surgical treatment. J Thorac Cardiovasc Surg 1945;14:347

8 Valiathan MS, Weldon CS, Bender HW Jr, Topaz SR, Gott VL. Resection of aneurysms of the descending thoracic aorta using a GBH-coated shunt bypass. J Surg Res 1968;8(5):197-205

9 Debakey ME, Cooley DA, Crawford ES, Morris GC Jr. Aneurysms of the thoracic aorta; analysis of 179 patients treated by resection. J Thorac Surg 1958;36(3):393-420

10 Cooley DA, Debakey ME, Morris GC Jr. Controlled extracorporeal circulation in surgical treatment of aortic aneurysm. Ann Surg 1957;146(3):473-485, discussion 485-486
11 Bloodwell RD, Hallman GL, Beall AC Jr, Cooley DA, DeBakey ME. Aneurysms of the descending thoracic aorta: surgical considerations. Surg Clin North Am 1966;46(4):901-911

12 Donahoo JS, Brawley RK, Gott VL. The heparin-coated vascular shunt for thoracic aortic and great vessel procedures: a ten-year experience. Ann Thorac Surg 1977;23(6):507-513

13 Livesay JJ, Cooley DA, Duncan JM, Ott DA, Walker WE, Reul GJ Jr. Open aortic anastomosis: improved results in the treatment of aneurysms of the aortic arch. Circulation 1982; 66(2 Pt 2, Suppl 1) :I122-I127

14 Roberts AJ, Nora JD, Hughes WA, et al. Cardiac and renal responses to cross-clamping of the descending thoracic aorta. J Thorac Cardiovasc Surg 1983;86(5):732-741

15 Cooley DA, Techniques in Cardiac Surgery. 2nd ed. Philadelphia: WB Saunders Company; 1984:279

16 Svensson LG, Crawford ES, Hess KR, Coselli JS, Safi HJ. Experience with 1509 patients undergoing thoracoabdominal aortic operations. J Vasc Surg 1993;17(2):357-368, discussion 368-370

17 Coselli JS, LeMaire SA, Conklin LD, Köksoy C, Schmittling ZC. Morbidity and mortality after extent II thoracoabdominal aortic aneurysm repair. Ann Thorac Surg 2002;73(4):1107-1115, discussion 1115-1116 